\title{
Prospects of microwave processing: An overview
}

\author{
S DAS*, A K MUKHOPADHYAY, S DATTA and D BASU \\ Central Glass and Ceramic Research Institute, Kolkata 700 032, India
}

MS received 5 September 2007; revised 12 November 2008

\begin{abstract}
Microwave processing has been emerging as an innovative sintering method for many traditional ceramics, advanced ceramics, specialty ceramics and ceramic composites as well as polymer and polymer composites. Development of functionally gradient materials: joining; melting; fibre drawing; reaction synthesis of ceramics; synthesis of ceramic powder, phosphor materials, whiskers, microtubes and nanotubes; sintering of zinc oxide varistors; glazing of coating surface and coating development have been performed using microwave heating. In addition, microwave energy is being explored for the sintering of metal powders also. Ceramic and metal nanopowders have been sintered in microwave. Furthermore, initiatives have been taken to process the amorphous materials (e.g. glass) by microwave heating. Besides this, attempt has been made to study the heating behaviour of materials in the electric and magnetic fields at microwave frequencies. The research is now focused on the use of microwave processing for industrial applications.
\end{abstract}

Keywords. Microwave processing; ceramics; metal; polymer; composite; glass.

\section{Introduction}

The application of microwave energy to the processing of various materials such as ceramics, metals and composites offers several advantages over conventional heating methods. These advantages include unique microstructure and properties, improved product yield, energy savings, reduction in manufacturing cost and synthesis of new materials (Sutton 1989).

Microwave heating is fundamentally different from the conventional one in which thermal energy is delivered to the surface of the material by radiant and/or convection heating that is transferred to the bulk of the material via conduction. In contrast, microwave energy is delivered directly to the material through molecular interaction with the electromagnetic field. Microwave heating is the transfer of electromagnetic energy to thermal energy and is energy conversion rather than heat transfer. Since microwaves can penetrate the material and supply energy, heat can be generated throughout the volume of the material resulting in volumetric heating. Hence, it is possible to achieve rapid and uniform heating of thick materials. Therefore, the thermal gradient in the microwaveprocessed material is the reverse of that in the material processed by conventional heating. In conventional heating, slow heating rates are selected to reduce steep thermal gradient leading to process-induced stresses. Thus, there is a balance between processing time and product quality. During microwave processing, the potential exists to

\footnotetext{
*Author for correspondence (sumana@cgcri.res.in)
}

reduce processing time and enhance product quality as microwaves can transfer energy throughout the whole volume of the material. In this case, energy transfer occurs at a molecular level that can have some additional advantages. When microwave energy is in contact with materials having different dielectric properties, it will selectively couple with the higher loss tangent material. Therefore, microwaves can be used for the selective heating of the materials (Thostenson and Chou 1999).

The objective of this article is to present an overview of the microwave processing of different materials. Some recent applications of microwave heating to materials processing are also described.

\section{Microwaves}

Microwaves are electromagnetic waves with wavelengths from $1 \mathrm{~mm}$ to $1 \mathrm{~m}$ and corresponding frequencies between $300 \mathrm{MHz}$ and $300 \mathrm{GHz} .0 .915 \mathrm{GHz}$ and $2.45 \mathrm{GHz}$ frequencies are commonly used for microwave heating. These frequencies are chosen for the microwave heating based on two reasons. The first is that they are in one of the industrial, scientific and medical (ISM) radio bands set aside for non-communication purposes. The second is that the penetration depth of the microwaves is greater for these low frequencies. However, heating is not necessarily increased with decreasing frequency as the internal field $(E)$ can be low depending on the properties of the material. $2 \cdot 45 \mathrm{GHz}$ is mostly used for household microwave ovens and $0.915 \mathrm{GHz}$ is preferred for industrial/ commercial microwave ovens. Recently, microwave fur- 
naces with variable frequencies from 0.9 to $18 \mathrm{GHz}$ have been developed for material processing (Sutton 1989; Thostenson and Chou 1999). Microwaves are coherent and polarized and can be transmitted, absorbed, or reflected depending on the material type (Sutton 1989).

\subsection{Microwave furnace}

Microwave furnace consists of three major components: the source, the transmission lines and the applicator. The source generates electromagnetic radiation and the transmission lines deliver the electromagnetic energy from the source to the applicator while the energy is either absorbed or reflected by the material in the applicator. Generally, the processing is performed within a metallic applicator (e.g. single mode applicator, traveling wave applicator and multimode applicator). The type of applicator used depends on the materials to be processed. The single mode applicator and the traveling wave applicator are successful in processing materials of simple geometries. However, the multimode applicator has the capability to produce large and complex components. Therefore, multimode systems are used for industrial applications (Thostenson and Chou 1999).

\subsection{Microwave-material interaction}

Microwave energy is transferred to the material by interaction of the electromagnetic field at the molecular level. The dielectric properties determine the effect of the electromagnetic field on the material (Thostenson and Chou 1999). The interaction of microwaves with a dielectric material results in translational motions of free or bound charges and rotation of the dipoles. The resistance of these induced motions due to inertial, elastic, and frictional forces causes losses resulting in volumetric heating (Sutton 1989).

The power absorbed per unit volume, $P\left(\mathrm{~W} / \mathrm{m}^{3}\right)$ is expressed as (Sutton 1989):

$$
P=\sigma|E|^{2}=2 \pi f \varepsilon_{0} \varepsilon_{\mathrm{r}}^{\prime} \tan \delta|E|^{2},
$$

where $E(\mathrm{~V} / \mathrm{m})$ is the magnitude of the internal field, $\sigma$ the total effective conductivity $(\mathrm{S} / \mathrm{m}), f$ the frequency $(\mathrm{GHz}), \varepsilon_{0}$ the permittivity of free space $\left(\varepsilon_{0}=8.86 \times\right.$ $\left.10^{-12} \mathrm{~F} / \mathrm{m}\right), \varepsilon_{\mathrm{r}}^{\prime}$ the relative dielectric constant and tan $\delta$ the loss tangent.

Equation (1) demonstrates that the power absorbed varies linearly with the frequency, the relative dielectric constant, loss tangent and the square of the electric field.

The penetration depth of microwaves $(D)$ at which the incident power is reduced by one half is expressed as (Sutton 1989):

$$
D=3 \lambda_{0} / 8 \cdot 686 \pi \tan \delta\left(\varepsilon_{\mathrm{r}}^{\prime} / \varepsilon_{0}\right)^{1 / 2},
$$

where $\lambda_{0}$ is the incident or free-space wavelength.
The relative dielectric constant and the loss tangent are the parameters that describe the behaviour of a dielectric material under the influence of the microwave field. During heating, the relative dielectric constant and the loss tangent change with temperature (figures 1a-b) (Sutton 1989).

\subsection{Thermal runaway}

When ceramics are processed in non-uniform electromagnetic fields, the local temperature varies within the material. If a local area reaches the critical temperature before the rest of the material, it begins to get heated more rapidly. Thus, the temperature of that local region begins to increase even more resulting in localized thermal runaway leading to high enough stresses and material fracture (Thostenson et al 1999).

\section{Applications}

Excellent reviews have been provided on the general aspects of microwave processing by several experts (Sutton
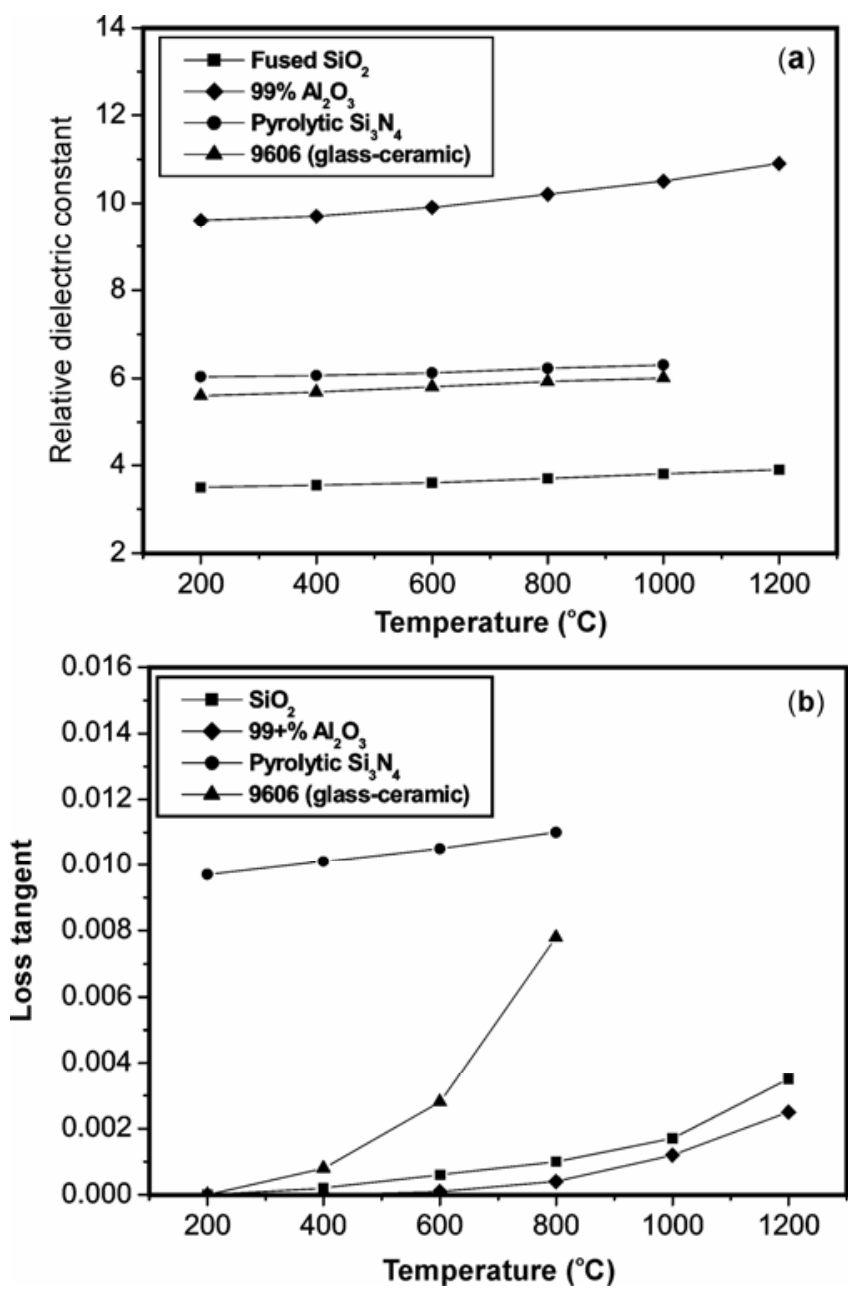

Figure 1. (a) Relative dielectric constant vs temperature and (b) loss tangent vs temperature (Sutton 1989). 
1989; Clark and Sutton 1996; Agrawal et al 1998, 2004, 2005a; Thostenson and Chou 1999). The present review provides an overview of the microwave processing of a variety of conventional as well as advanced materials. Applications of microwave processing are indeed very wide. For instance, it can include processing of solution and suspension, drying, organic material burnout, clinkering, sintering of ceramics and ceramic composites, preparation of specialty ceramics, plasma processing, processing of polymers and polymer composites, fabrication of functionally graded materials, joining, fibre drawing, melting, reaction synthesis of ceramics and a host of very promising, new, advanced applications. Since application range covers a very wide spectrum, only general achievements have been highlighted leaving behind the critical issues.

\subsection{Solution and suspension}

In this application, the aim was to reduce the time requirement for the wet chemical analysis of minerals, ceramics and alloys by increasing their dissolution rates in acids (US Bureau of Mines 1983). Also, the process of slip casting sanitary ware could be made faster by heating the slip to $65^{\circ} \mathrm{C}$ and then hardening the ware in the molds after casting (Guerga and Hailler 1973). Microwave assisted liquid phase deposition process was utilized to obtain nanocrystalline anatase titania from low concentration precursor solution (Zhang L -X et al 2006).

\subsection{Drying}

Drying by this technology has been shown to be particularly effective for removing low water content from thick section. Water is driven away from the interior section due to volumetric heating (Krupa et al 1993; Sieke 1993; Ananthakumar et al 1998; Segerer 1998; Anon 2001). Hence, this technology is commercially utilized for foundry applications (Sutton 1989). This kind of heating permits efficient and faster drying of the insulating materials (Segerer 1998). Even, uniformly dispersed alumina30 vol.\% SiC particulate gel composite was prepared by this process (Ananthakumar et al 1998). Further, dehydration of sodium carbonate monohydrate has also been performed using this technique (Seyrankaya and Ozalp 2006).

\subsection{Organic material burnout}

Selective heating as well as volumetric heating has been extensively utilized for the binder burnout purposes during processing of the green ceramics (Sutton 1989; Leonelli et al 2004). Further applications are also upcoming.

\subsection{Clinkering}

The low incident power $(300 \mathrm{~W})$ and the short reaction time $(\approx 7 \mathrm{~min}$ ) have made this method promising for heating the refractory materials to produce clinker (Quemeneur et al 1983a). A microwave generator giving variable power from 0 to $3 \mathrm{~kW}$ at $2.45 \mathrm{GHz}$ central frequency was used by Quemeneur et al for clinkering. Quemeneur et al (1983a) also studied clinkering of different clinker raw materials using microwave energy at $2.45 \mathrm{GHz}$. The properties of the microwave cement were close to those of the industrial cement. Microwave processing was utilized to prepare regular and coloured cement clinkers at $2.45 \mathrm{GHz}$ at a lower clinkering temperature than that required for conventional processing (Fang et al 1996b). Clinkering of sulfoalumina cement was also achieved using microwave (Long et al 2002).

\subsection{Sintering of ceramics and ceramic composites}

3.5a Structural and functional ceramics: Bulk alumina, zinc oxide, silicon carbide, zirconia-toughened alumina, $\mathrm{MgAl}_{2} \mathrm{O}_{4}$, Y-PSZ, hydroxyapatite, Y-TZP/20wt $\% \mathrm{Al}_{2} \mathrm{O}_{3}$ composites and glass matrix composites etc have been prepared by this technique (Fang et al 1993; Goldstein et al 1998, 1999; Lee and Case 1999; Xie et al 1999; Travitzky et al 2000; Boccaccini et al 2001; Mandal et al 2001; Mukhopadhyay et al 2001). Figures 2a-c show the mechanical properties of microwave sintered zinc oxide (Mandal et al 2001).

Similarly, for even commercial grade, less pure titania powder, high relative density $(\sim 96 \%)$ could be achieved while similar schedule $\left(1300^{\circ} \mathrm{C}, 1 \mathrm{~h}\right)$ in a muffle furnace led to only $\sim 85 \%$ relative density (figure 3 ) (Das et al 2005). The sintered titania had finer microstructure (average grain size $\sim 1.29 \mu \mathrm{m}$, figure $4 \mathrm{a}$ ) in comparison to that (average grain size $\sim 3.69 \mu \mathrm{m}$ ) of the conventionally sintered titania (figure $4 \mathrm{~b}$ ). In addition, sintered 9Y-PSZ with very high relative density ( $\sim 97 \%$ ) and equiaxed grains $(\sim 15 \mu \mathrm{m})$ was also achieved by microwave sintering for only $35 \mathrm{~min}$ at $1625^{\circ} \mathrm{C}$ (Upadhyaya et al 2001).

3.5b Bio-ceramics: The hydroxyapatite (HAp) ceramics were sintered in microwave with significant time and energy savings (Fang et al 1992, 1994). Fang et al (1995) showed that for transparent HAp, the total processing time from start to finish of the sintering process $(5 \mathrm{~min}$ soaking at $1150^{\circ} \mathrm{C}$ ) was $\sim 20 \mathrm{~min}$ for microwave sintering while the same was about $4 \mathrm{~h}$ in the case of conventional sintering. Hydroxyapatite ceramics with tailored mechanical properties have also been fabricated by this technique (Rodríguez-Lorenzo et al 2003).

3.5c Composites: Lower sintering temperatures and times were required to microwave sinter $\mathrm{WC} / \mathrm{Co}$ composi- 
tes, which are widely used for cutting, drilling tools and wear resistant applications. The sintered samples exhibited smaller WC grains and finer, more uniform distribution of cobalt binder that resulted in better resistance towards corrosion and erosion (Breval et al 2005). Recently, microwave assisted powder metallurgy method has been used to form nano-yttria reinforced magnesium composite (Tun and Gupta 2007).

\subsection{Specialty ceramics}

This technology is being increasingly employed for many specialty ceramics (Fang et al 1996a, 2004a, b; Xie et al 1998; Vaidhyanathan et al 2000, 2004; Cheng et al 2001a, 2002a; Huang et al 2001; Hsu and Huang 2001; Kutty et al 2001; Oh et al 2001; Rhee et al 2001; Lo et al 2002; Yadoji et al 2003; Agrawal 2006). Microwave sintered Ni$\mathrm{Zn}$ ferrites showed lower coercivity, lower dielectric constant
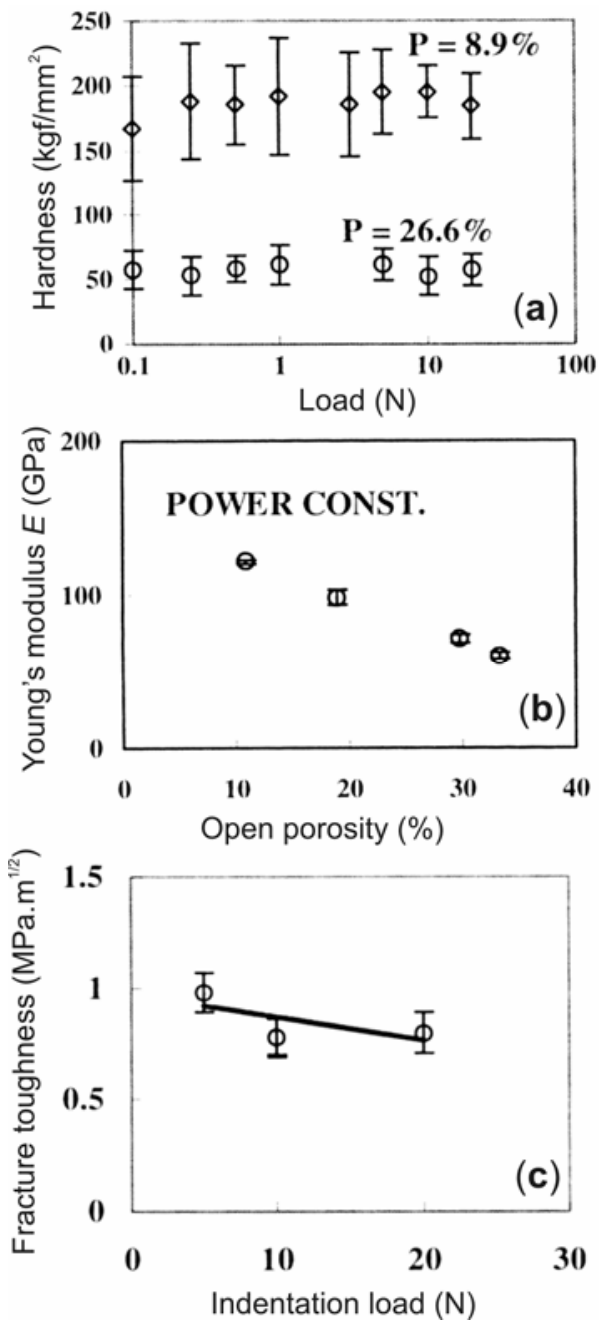

Figure 2. Mechanical properties of microwave sintered zinc oxide: (a) hardness vs load, (b) Young's modulus vs vol. \% open porosity and (c) fracture toughness vs load (Mandal et al 2001). and higher magnetization values (Yadoji et al 2003). Similarly, reasonable translucency was obtained in the AlN samples at $1850^{\circ} \mathrm{C}$ for a much shorter time of only 30-60 min (Cheng et al 2002a). Fully transparent aluminium oxynitride (ALON) ceramics were prepared by microwave reactive sintering at $1800^{\circ} \mathrm{C}$ for $1 \mathrm{~h}$ in a nitrogen atmosphere (c.f. conventional sintering for 20-100 h at $>1850^{\circ} \mathrm{C}$ ), (figure 5) (Cheng et al 2001a). Microwave sintering of $\mathrm{Ni}$ electrode multi-layer ceramic capacitors (MLCCs) at $1250^{\circ} \mathrm{C}$ in the reducing atmosphere led to dense and uniform product without any cracks or delaminations (Fang et al 2004b). A strong and relatively porous glass-ceramic product was also developed by microwave sintering of flyash (Fang et al 1996a).

\subsection{Plasma processing}

Two variants of this emerging novel technique are: microwave plasma chemical vapour deposition (MPCVD) and microwave plasma induced sintering (MPIS). Diamond and diamond-like films were formed by MPCVD (Kamo et al 1983). The MPIS method helped to sinter $\mathrm{Al}_{2} \mathrm{O}_{3}$ ceramics containing $0.25 \mathrm{wt} \% \mathrm{MgO}$ to $99.9 \%$ relative density in nitrogen plasma at $1660^{\circ} \mathrm{C}$ in $<10 \mathrm{~min}$ (Kemer and Johnson 1985). Plasma activated sintering of AIN powders to near theoretical density was achieved within $5 \mathrm{~min}$ at $1730^{\circ} \mathrm{C}$ (Groza et al 1992).

\subsection{Polymer and polymer matrix composites}

This processing approach has reduced the processing times and improved the mechanical properties of thermosetting and thermoplastic polymer and polymer matrix composites e.g. epoxy resin, glass fibre reinforced epoxy composite, carbon fibre reinforced epoxy composite, poly-ether-etherketone (PEEK) coating, SiC particle reinforced PEEK coating (Haran et al 1965; Lee and Springer 1984; Chen et al 1993; Zhang G et al 2006). Dipole structure, frequency of processing, selective coupling, fabrication temperature,

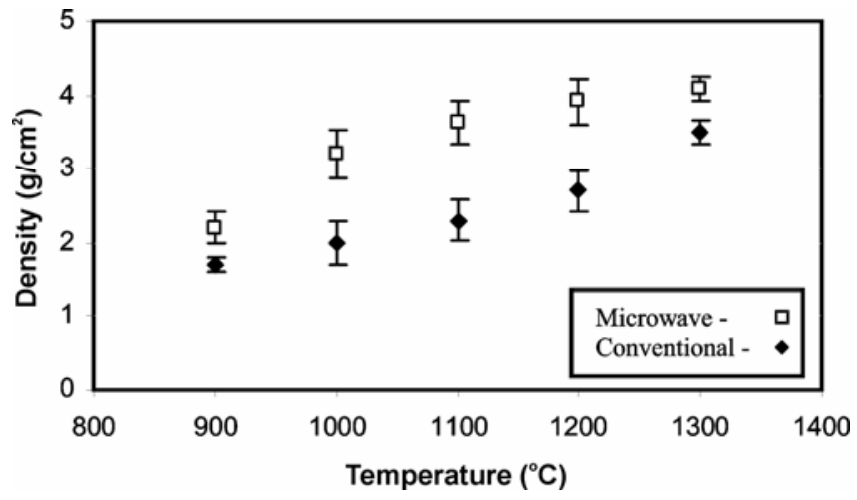

Figure 3. Density values of microwave and conventionally sintered titania samples. 


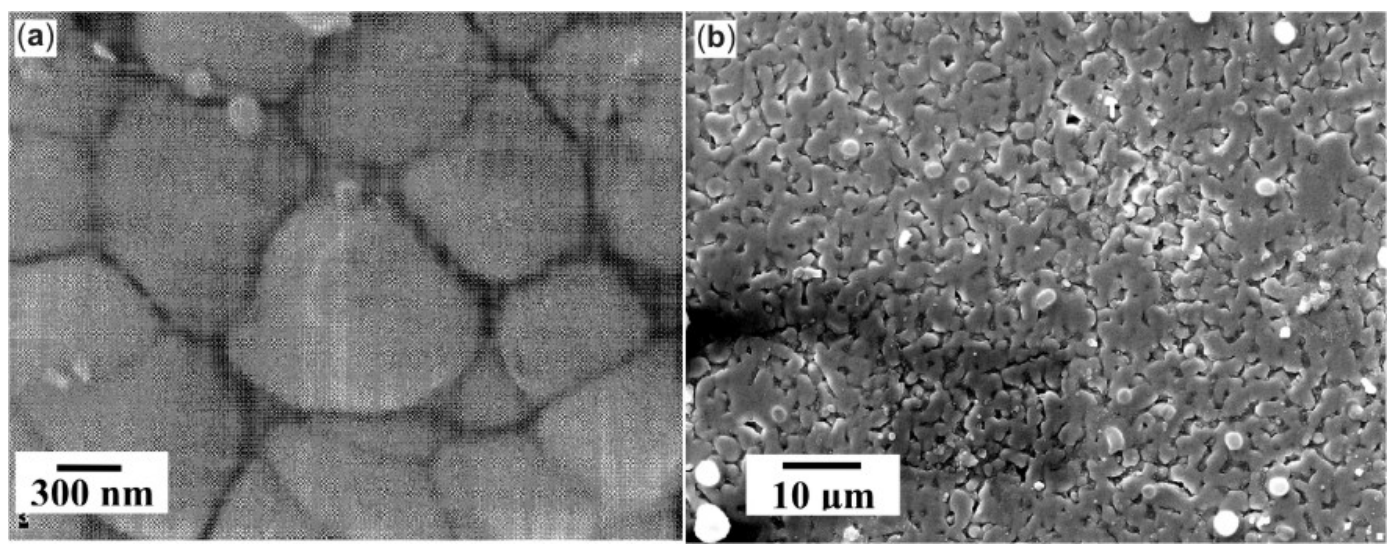

Figure 4. Microstructures of sintered titania samples: (a) microwave and (b) conventional.

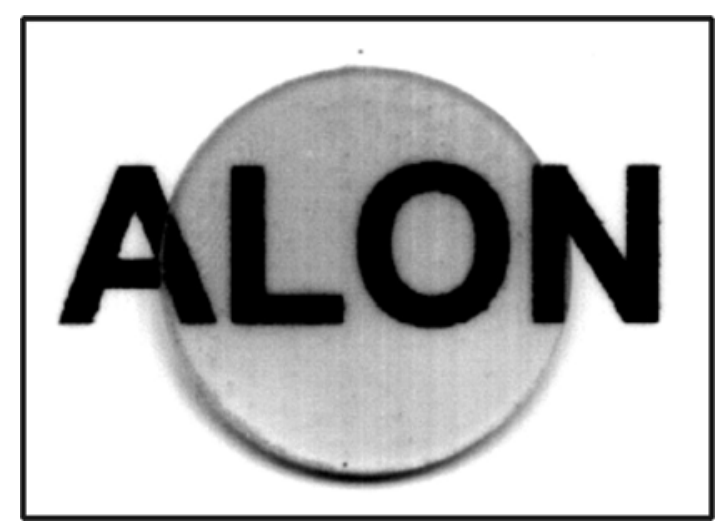

Figure 5. Fully transparent ALON sample (Cheng et al 2001a).

chemical nature of additives and fillers etc all influence the processing (Thostenson and Chou 1999).

\subsection{Functionally graded materials (FGMs)}

Compositional variations in the FGMs (e.g. steel-WC/Co) are ensured in this method due to shorter processing time (Agrawal 2005b). Ti-B-based FGMs were produced by microwave-activated combustion synthesis (Cirakoglu et al 2002). Better compositional control in calcium phosphate, titania and silver FGMs was also made possible (Katakam et al 2003).

\subsection{Joining}

Reliable joining of ceramic materials e.g. strong aluminaalumina joints (Al-Assafi et al 1991), other joints (Meek and Blake 1986; Palaith and Silberglitt 1989; Cheng et al 1999; Fukushima et al 1990; Cawley 1998; Zeng et al 2003), joints of alumina-30\%zirconia composites (Aravindan and Krishnamurthy 1999) etc is an issue of significant technological importance addressed by this processing route.

\subsection{Fibre drawing}

Attempt was made to draw ultra pure quartz optical fibres at temperatures above $2000^{\circ} \mathrm{C}$ using microwave heating in a specially designed single mode applicator. The amount of material blown away by the torching during tube collapse as well as energy cost, was reduced in the microwave process. The optical fibre quality was comparable with that obtained by the standard process (Hassler and Johansen 1988).

\subsection{Melting}

The feasibility of this emerging technique is well demonstrated for the melting of ceramics (Berteaud and Badot 1976). Melting of silica gels was also achieved by microwave heating (Roy et al 1985). Rapid heating and melting were observed in $\mathrm{Na}, \mathrm{K}$ and Cs containing zeolites with microwave energy (Komarneni and Roy 1986). Glasses were melted using microwave radiation by Duval et al (1997). Microwave has been used to melt even bulk metals (Barmatz et al 2000).

\subsection{Reaction synthesis of ceramics}

In a very interesting work, Mathis et al (1995a) studied microwave assisted solid state reaction of alumina and titania to form aluminium titanate. $\mathrm{MgAl}_{2} \mathrm{O}_{4}$ spinel was also obtained through the solid state reaction between magnesium oxide $(\mathrm{MgO})$ and aluminium oxide $\left(\mathrm{Al}_{2} \mathrm{O}_{3}\right)$ along with $1 \mathrm{wt} . \%$ of $\mathrm{CaO}$ as an additive at about $1400^{\circ} \mathrm{C}$ for $\sim 4 \mathrm{~min}$ (c.f. conventional route: $96 \mathrm{~h}$ at $1400^{\circ} \mathrm{C}$, Gómez et al 2004). This novel process helped to synthesize $\beta$-SiAlON within only $15 \mathrm{~min}$ at $1500^{\circ} \mathrm{C}$ (Mathis et 
al 1995b). Even, synthesis of phase pure ALON was achievable (Cheng et al 1999).

\section{Relatively newer applications}

\subsection{Synthesis of ceramic powder}

Cr-substituted lithium ferrite powder $\left[\mathrm{Li}_{0.5} \mathrm{Fe}_{2.5-x} \mathrm{Cr}_{x} \mathrm{O}_{4}\right.$ $(0 \leqq x \leqq 1 \cdot 0)]$ with small and uniform sized particles was successfully synthesized within only a few min by microwave-induced combustion method ( $\mathrm{Fu}$ et al 2006). Binner et al (1995) synthesized titanium carbide and tantalum carbide by carbothermal reduction of the oxides. Further, synthesis of high phase pure $\beta$-SiC powder using microwave irradiation (Ramesh et al 1994), $\mathrm{LiAl}_{0.1}$ $\mathrm{Mn}_{1.9} \mathrm{O}_{4}$ powder by microwave assisted sol-gel processing (Zhou et al 2006), all demonstrate the utilities of this technique.

\subsection{Synthesis of phosphor materials}

$\mathrm{ZnS}$ based phosphor materials were prepared within a much shorter time $(20 \mathrm{~min})$ in a domestic microwave oven $(2.45 \mathrm{GHz}, 900 \mathrm{~W})$ (Sundar Manoharan et al 2001). Researchers also synthesized fine particles of $\mathrm{Sr}_{2} \mathrm{CeO}_{4}$ by hydrothermal reaction at $200^{\circ} \mathrm{C}$ for $30 \mathrm{~min}$ with a pressure of 200 psi in a microwave accelerated reaction system $(2.45 \mathrm{GHz}, 1200 \mathrm{~W})$ followed by calcination of the as-prepared material at $1000^{\circ} \mathrm{C}$ for $25 \mathrm{~h}$ in air (Khollam et al 2004). Synthesis of nanocrystalline $\mathrm{MMoO}_{4}$ $(\mathrm{M}=\mathrm{Ni}, \mathrm{Zn})$ phosphors was carried out by the modified citrate complex route using microwave irradiation $(2.45 \mathrm{GHz}, 1200 \mathrm{~W})$ under ambient air for $30 \mathrm{~min}$ (Ryu et al 2006).

\subsection{Synthesis of whiskers}

The application of this versatile technique helped the synthesis of ultra fine silicon carbide whiskers through the reduction of ultra fine silica powders with various forms of carbon (Dai et al 1997) and hydroxyapatite whiskers (Yoon et al 2005) with high aspect ratio by the hydrolysis of $\alpha$-tricalcium phosphate (figure 6). The hydrolysis reaction time for hydroxyapatite whiskers could be reduced by more than twice.

\subsection{Synthesis of microtubes}

Cheng et al (2004) showed that the colourless, contamination free, fully transparent, nearly perfect crystalline and hexagonal, hollow tubular shaped $\mathrm{ZnO}$ microtubes (wall thickness, $0 \cdot 5-1 \mu \mathrm{m}$ ) could be grown by microwave heating. This prospective area should receive more attention of the researchers.

\subsection{Synthesis of nanotubes}

The one-dimensional nanostructured materials have potential applications in ceramics, electronics, optics, magnetic storage, catalysis and chemistry, physics and biomedical sciences. This emerging area showed promise through synthesis of ordered array of CdS nanotubes (figures 7ac) (Ni et al 2004), $\mathrm{TiO}_{2}$ nanotubes (Wu et al 2005) and even carbon nanotubes (Yoon et al 2006).

\subsection{ZnO based ceramic varistors}

Varma et al (1996) prepared doped $\mathrm{ZnO}$ varistors using microwave reactive precursors in a domestic microwave oven $(600 \mathrm{~W}, 2.45 \mathrm{GHz})$. Such powders were further sintered to higher density ( $>95 \%$ ) varistors having desirable microstructure and non-ohmic properties. Nan Lin et al (2001) used microwave energy to sinter $\mathrm{ZnO}$ varistors having high density and improved electrical properties in an applicator $(1 \mathrm{~kW}, 2.45 \mathrm{GHz})$. Utilizing microwave processing, Agrawal et al (2002) sintered zinc oxide varistors with better density, finer grain size, more uniform microstructure and better electrical properties through significant reduction in the processing time.

\subsection{Glazing of coating}

In a singular effort, significant improvement in the microhardness $(\sim 1550 \mathrm{Hv})$ and the surface finish $\left(R_{\mathrm{a}} \sim 1 \mu \mathrm{m}\right)$ was observed with the microwave treated atmospheric plasma sprayed alumina-titania composite coating (Sharma et al 2001).

\subsection{Crystallization of glass}

Monoclinic celsian was obtained from $10 \% \mathrm{CuO}$ seeded barium aluminosilicate glass using this novel technique at

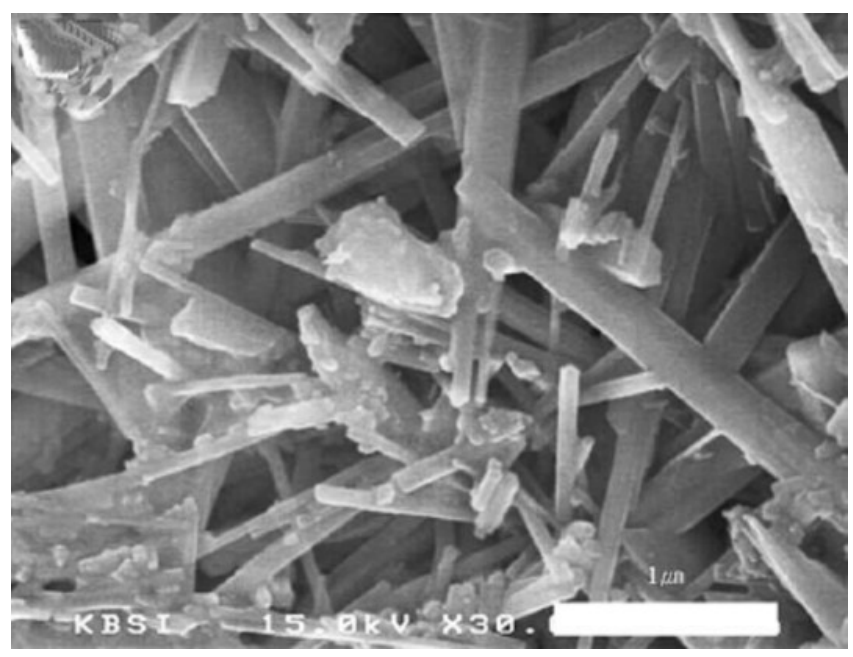

Figure 6. Hydroxyapatite whisker (Yoon et al 2005). 


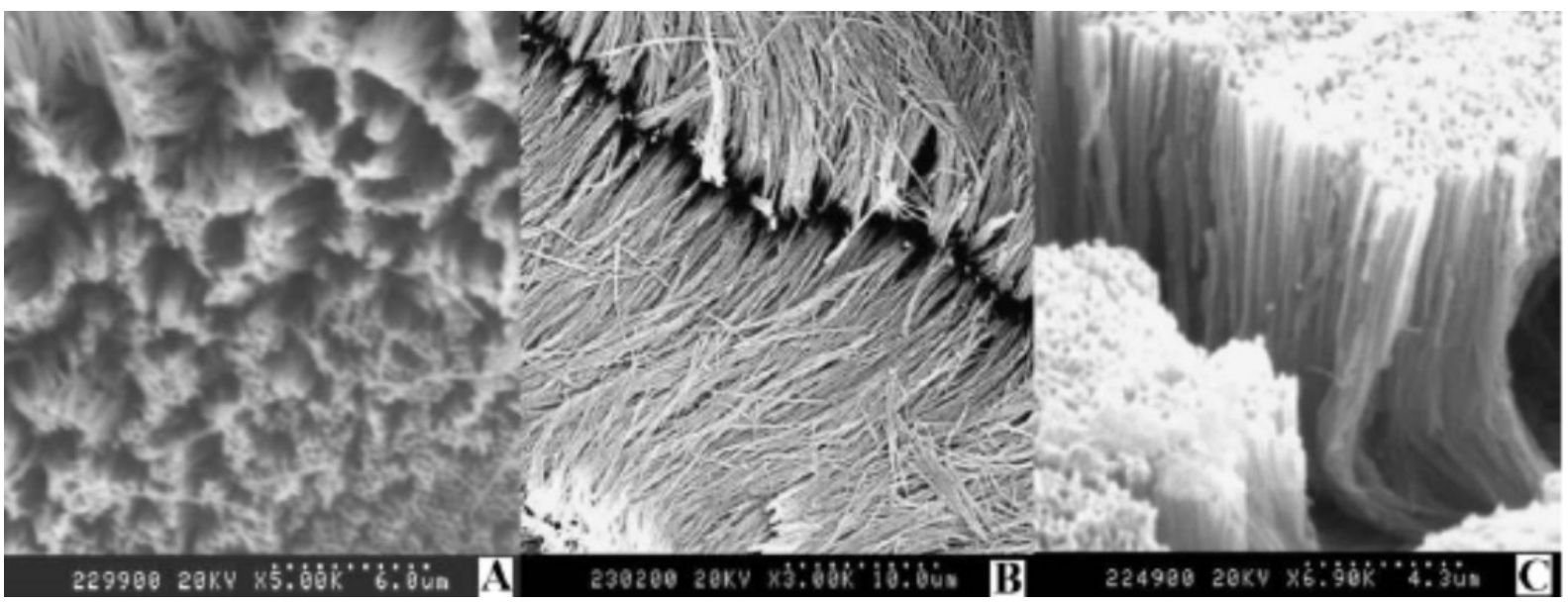

Figure 7. CdS nanotubes array: (A) survey picture, $(\mathbf{B})$ and $(\mathbf{C})$ lateral pictures (Ni et al 2004).

$1300^{\circ} \mathrm{C}$ for only $15 \mathrm{~min}$ in a $2.45 \mathrm{GHz}$ microwave field (Cozzi et al 1993). Siligardi et al (1996) investigated the effect of microwave on bulk crystallization of glasses belonging to $\mathrm{M}_{2} \mathrm{O}-\mathrm{CaO}-\mathrm{SiO}_{2}-\mathrm{ZrO}_{2}$ system (where $\mathrm{M}=$ $\mathrm{Li}, \mathrm{Na}, \mathrm{K})$ in a commercial microwave oven $(900 \mathrm{~W}$, $2.45 \mathrm{GHz}$ ). The glass samples heat treated by microwave energy showed surface and bulk crystallization while only surface crystallization was observed in the glass samples heat treated by conventional method. The sintering and devitrification in the ternary $\mathrm{CaO}-\mathrm{ZrO}_{2}-\mathrm{SiO}_{2}$ glass system was studied by Siligardi et al (2000) in the temperature range $900-1050^{\circ} \mathrm{C}$ using commercial microwave oven $(900 \mathrm{~W}, 2.45 \mathrm{GHz})$.

\subsection{Coating development}

In our laboratory, this interesting method was used to develop aluminium oxide coating on commercial aluminium (Das et al 2003a, b). Figures 8a-b show the porous, thin coating $(\sim 42 \mu \mathrm{m})$ and dense, thick coating $(\sim 661 \mu \mathrm{m})$ developed by microwave heating of pre-oxidized aluminium samples $\left(600^{\circ} \mathrm{C}, 200 \mathrm{~h}\right)$ for 60 and $90 \mathrm{~min}$, respectively. In both of these two cases, smooth coating with crack free interface was observed. Microwave heating was also utilized to develop oxide coatings on blocks of commercial aluminium of various geometrical shapes (Das et al 2006). Experimental data showed that the geometrical term, i.e. the volume to surface ratio, had a significant effect on the microwave induced oxidation behaviour of the samples (figures 9a-b). Coating thickness and density gradually enhanced with increasing microwave exposure time. Protective oxide coating of varied thicknesses and microstructure was formed on commercial aluminium using this novel technique by suitable adjustments of the processing parameters.

Crystallization of $\mathrm{MgO}-\mathrm{Al}_{2} \mathrm{O}_{3}-\mathrm{TiO}_{2}$ based glass coatings with identical composition was conducted in our laboratory by both microwave and conventional heat treatment processes. Finer crystallites were generated in the glass coating by microwave processing than the sizes of the crystallites obtained in the conventionally processed coating (figures 10a-d). Microhardness and surface finish of the microwave processed glass-ceramic coatings were improved (figures 11-12) than those of the coatings processed by conventional heating (Das et al 2008b).

\subsection{Sintering of metal powder}

In an unprecedented approach, sintering of fine metallic powders, intermetallic compounds and alloys was achieved by this process wherein the sintered products showed better properties (Gerdes et al 1996; Gedevanishvili et al 1999; Roy et al 1999; Saitou 2006). Recently, $\mathrm{Mg}-\mathrm{Cu}$ nanocomposites have been developed using microwaveassisted sintering method (Wong and Gupta 2007). Unlike bulk metals that act as reflector, it is believed that in finely divided metallic powder, multiple scattering coupled with eddy current loss play a significant role in microwave absorption (Roy et al 1999).

\subsection{Preparation of nanomaterials}

Nanomaterials have been developed by several methods e.g. thermochemical process (Lee and Kim 2004), hydrothermal treatment (Pitisescu et al 2004) and microwaveassisted synthesis method (Rao et al 1999) etc. Microwave-assisted solvothermal method was also used for the synthesis of oxide nanomaterials e.g. $\mathrm{MgO}, \mathrm{NiO}, \mathrm{ZnO}$, $\mathrm{Al}_{2} \mathrm{O}_{3}, \mathrm{Fe}_{2} \mathrm{O}_{3}, \mathrm{ZrO}_{2}$ etc (Rao et al 2005). Nanocrystalline anatase $\mathrm{TiO}_{2}$ powder was synthesized utilizing microwave hydrothermal method (Vadivel Murugan et al 2006). Apte et al (2006) synthesized nanosized $\mathrm{Mn}_{3} \mathrm{O}_{4}$ powder by microwave digestion technique. Microwave induced combustion method was utilized to prepare cadmium substituted lithium ferrites $(3 \cdot 5-16.8 \mathrm{~nm})$ with general formula, 
$\mathrm{Li}_{0.5-x / 2} \mathrm{Cd}_{\mathrm{x}} \mathrm{Fe}_{2 \cdot 5-x / 2} \mathrm{O}_{4}$ (where $x=0.45,0 \cdot 5,0 \cdot 55,0 \cdot 6,0.65$, $0 \cdot 7)$. The saturation magnetization $\left(M_{\mathrm{s}}\right)$ and the hysteresis loss per cycle of the samples were in the range of 10.45 $35.23 \mathrm{emu} / \mathrm{g}$ and $25.51-65.15 \mathrm{erg} / \mathrm{cc} / \mathrm{cycle}$, respectively. All the samples showed the single domain behaviour. The Curie temperatures obtained using the susceptibility data were in the range of $210-300^{\circ} \mathrm{C}$. The d.c. resistivity was minimum $\left(9 \times 10^{4} \Omega \mathrm{cm}\right)$ for the sample with $x=0.55$ whereas the dielectric constant for the same composition was $1200 \times 10^{3}$. The dielectric constant and d.c. resistivity showed an inverse trend with each other (Watawe et al 2006).

\subsection{Sintering of nanomaterials}

Recently, nanophase $\mathrm{TiO}_{2}, \mathrm{Cu}$ metal powder and $\mathrm{MgO}$ have been sintered by this novel processing (figure 13) with very fine microstructures (Fang et al 2004a; Agrawal 2006). The nanocrystalline hydroxyapatite was sintered by microwave energy with high density (>96\% T.D. at $1100^{\circ} \mathrm{C}$ for $30 \mathrm{~min}$ soaking time), fine-grained microstructure and improved mechanical properties i.e. high
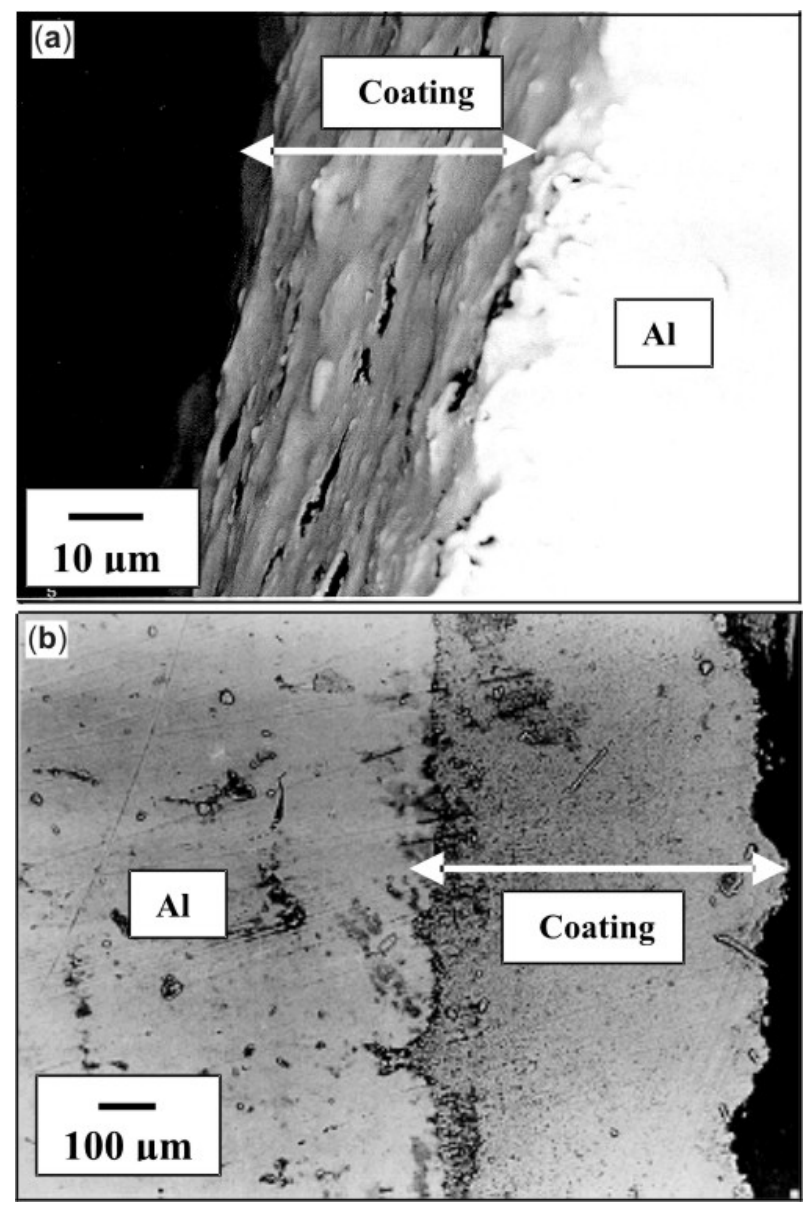

Figure 8. (a) Porous, thin coating grown by $60 \mathrm{~min}$ microwave heating and (b) dense, thick coating developed by $90 \mathrm{~min}$ microwave heating. fracture toughness and hardness (Ramesh et al 2007). Huang et al (2007) sintered tetragonal $\mathrm{ZrO}_{2}$ polycrystalline (TZP) composites with 2 wt. $\% \mathrm{Al}_{2} \mathrm{O}_{3}$ and co-stabilized with $1 \mathrm{~mol} \% \mathrm{Y}_{2} \mathrm{O}_{3}$ and 4,6 or $8 \mathrm{~mol}^{\circ} \mathrm{CeO}_{2}$ at $1450^{\circ} \mathrm{C}$ for $20 \mathrm{~min}$ in a single mode $2.45 \mathrm{GHz}$ microwave furnace. The microwave sintered ceramics showed finer and more uniform microstructures as compared to the conventionally sintered samples. Comparable hardness and toughness values were obtained for both the microwave and conventionally sintered samples. Nano-crystalline $\mathrm{La}_{1-x}$ $\mathrm{M}_{x} \mathrm{Ga}_{1-y} \mathrm{~N}_{y} \mathrm{O}_{3 \pm \delta}(\mathrm{M}=\mathrm{Sr}$; $\square$ (vacancy), $x=-0 \cdot 10$ to $0 \cdot 15$; $\mathrm{N}=\mathrm{Mn}, \mathrm{Mg} ; y=-0 \cdot 10$ to $0 \cdot 15$ ) compositions were synthesized by various wet chemical methods. The pellets made from these powders were microwave sintered at $\sim 1200^{\circ} \mathrm{C}$ in a very short interval of time $(30 \mathrm{~min})$. The conductivity of the sintered pellet was found to be $\sim 0.01-0.21 \mathrm{~S} \mathrm{~cm}^{-1}$ at $550-1000^{\circ} \mathrm{C}$ temperature range, respectively (Jena and Rambabu 2007).

\subsection{Decrystallizing solid crystalline titania}

In a promising effort, the rutile structure oxides were transformed to a noncrystalline state by a very short dura-
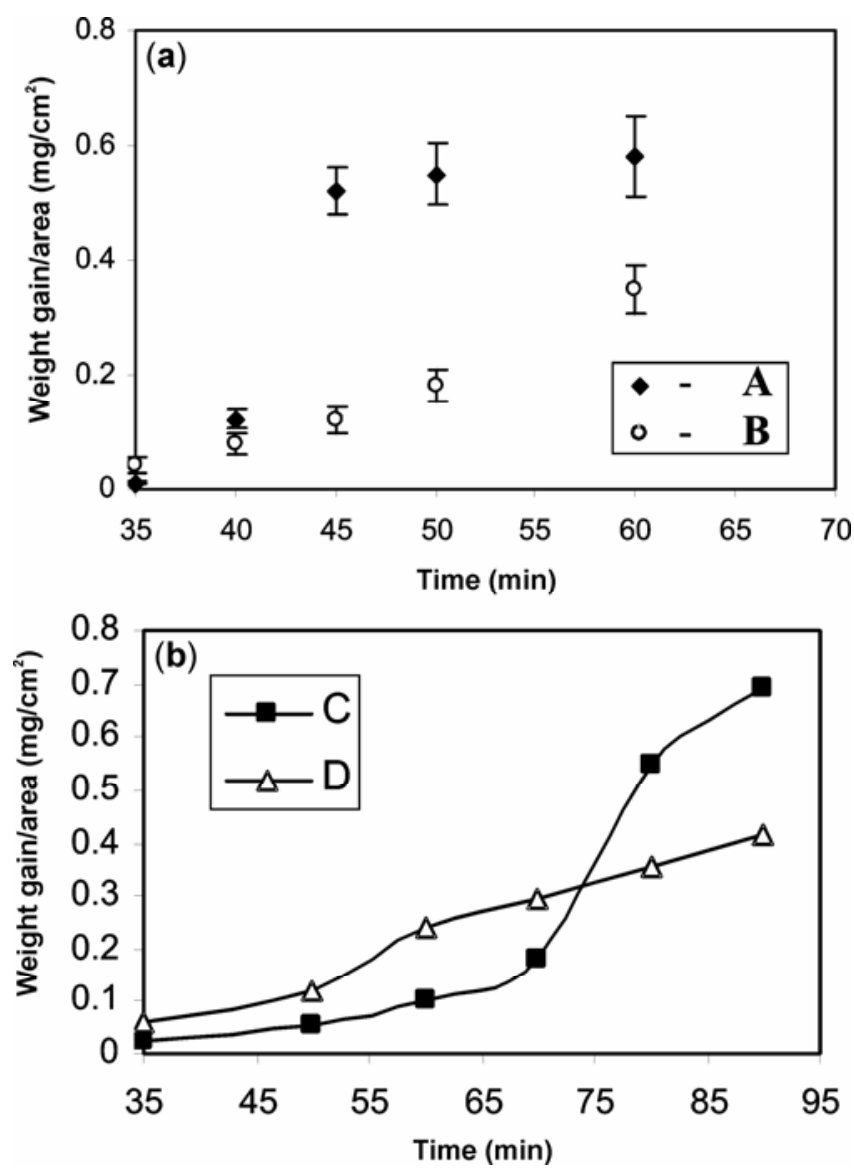

Figure 9. Weight gain data for pre-oxidized $\left(615^{\circ} \mathrm{C}, 4 \mathrm{~h}\right)$ samples: (a) sample A (hollow cylinder) and sample B (solid cylinder) and (b) sample C (solid cube) and sample D (thin rectangular block). 

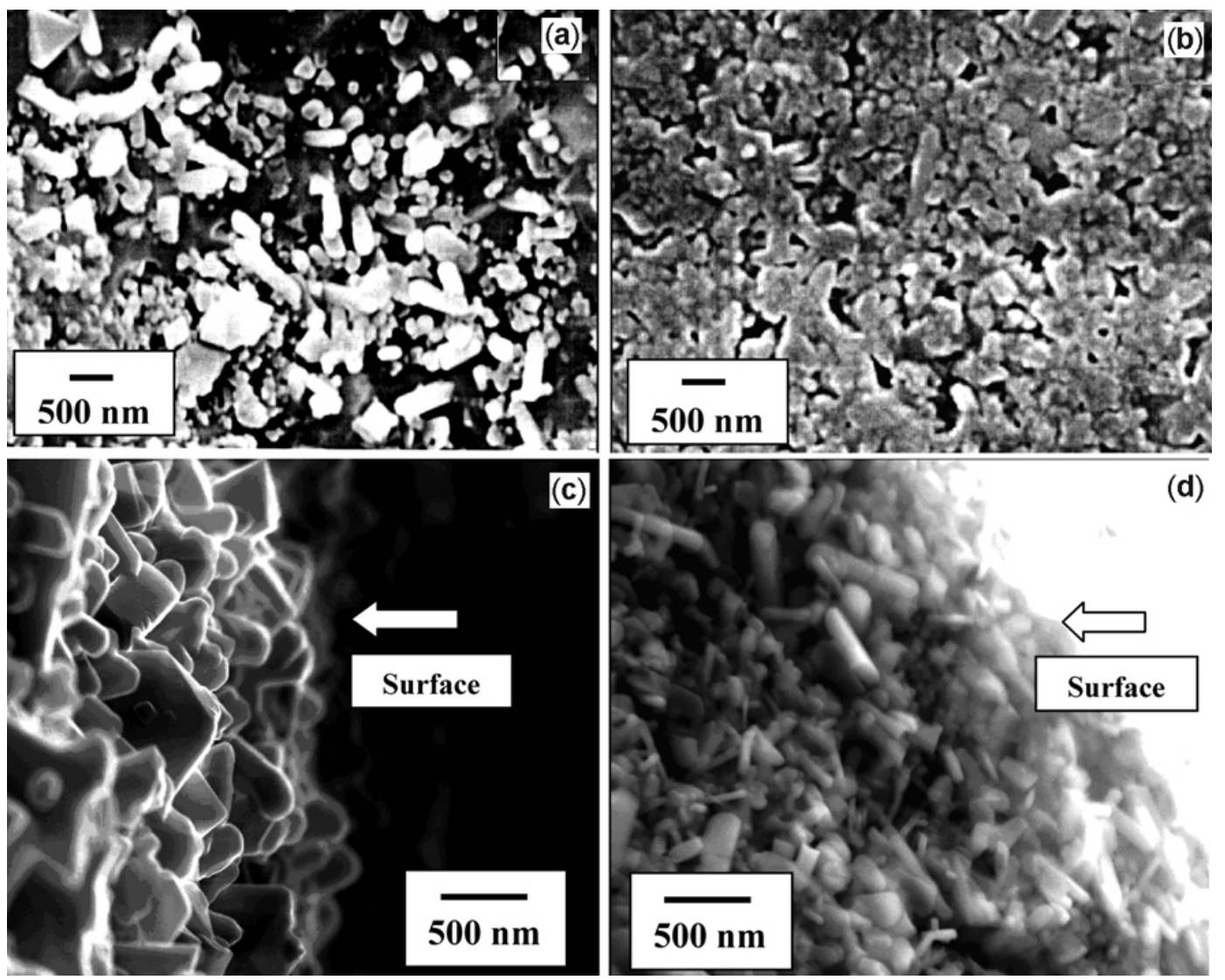

Figure 10. Surface microstructures of the glass-ceramic coatings obtained by heat treatments of the glass coatings for $90 \mathrm{~min}$ at $880^{\circ} \mathrm{C}$ followed by $90 \mathrm{~min}$ at $1020^{\circ} \mathrm{C}$ : (a) conventional, (b) microwave and crosssectional microstructures showing surface regions of the similar coatings, (c) conventional and (d) microwave.

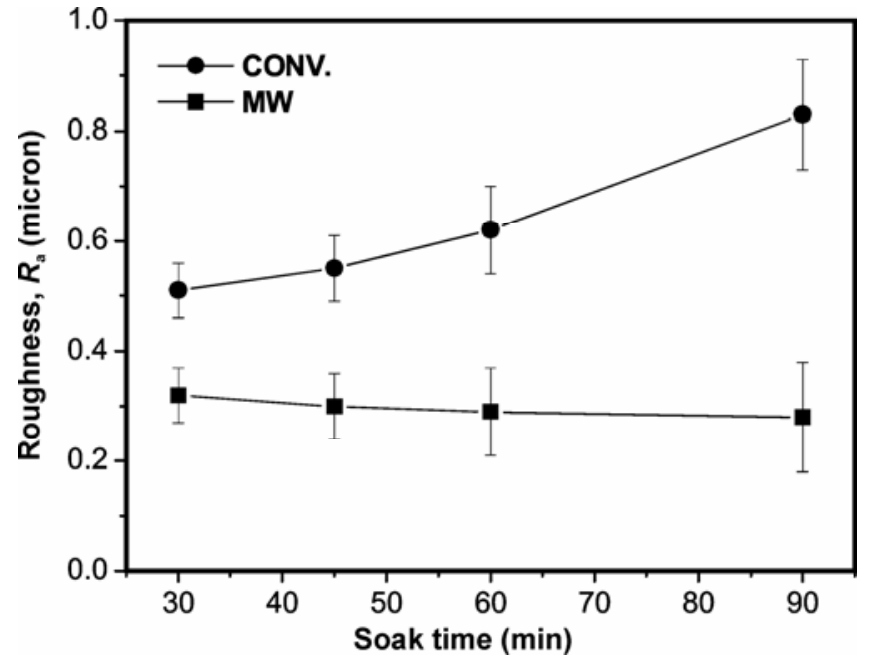

Figure 11. Typical surface roughness values of the microwave and conventionally processed glass-ceramic coatings.

tion treatment in the a.c. magnetic field at $2.45 \mathrm{GHz}$ (Roy et al 2005).

\subsection{Core-shell type $\mathrm{Al}_{-} \mathrm{Al}_{2} \mathrm{O}_{3}$ composite}

Further work in our laboratory showed that core-shell type $\mathrm{Al}-\mathrm{Al}_{2} \mathrm{O}_{3}$ composites could be developed by micro- wave heating of the as received, commercial grade, lowpurity aluminium powder and doped aluminium powder compacts (Das et al 2008a). Oxidation of aluminium powder compact was remarkably enhanced by the addition of certain dopants (e.g. $\mathrm{Mg}, \mathrm{Mg}-\mathrm{Si}, \mathrm{Al}_{2} \mathrm{O}_{3}$ ). Significant $\mathrm{Al}-$ $\mathrm{Al}_{2} \mathrm{O}_{3}$ composite growth was noted in the case of $5 \mathrm{wt} \%$ $\mathrm{Mg}$ doped aluminium powder compact. Figures $14 \mathrm{a}-\mathrm{d}$ show the typical micrographs of as received and treated aluminium powders.

\subsection{Heat treatment of $\mathrm{TiO}_{2}$ films}

Preliminary effort to provide crack resistant $\mathrm{TiO}_{2}$ films on the conducting glass substrates using microwave heating showed promising results (Hart et al 2005). However, further research is needed to clarify many unresolved issues.

\subsection{Industrial applications}

This include the curing, drying and dewaxing of ceramic moulds and shells used in the metal casting industries as well as slip casting of production shapes etc (Sutton 1989). Prospective applications encompass a much wider variety e.g. calcination, sintering, joining, plasma induced sinter- 
ing, clinkering of cement materials, heating of optical fibre preforms and process control in the ceramic industry (Metaxas et al 1993), polymerization, composite processing, bonding, microwave-assisted chemical vapour deposition, non-destructive evaluation etc (Fathi et al 1996), contaminated soil vitrification, volatile organic compounds treatment and recovery, waste sludge processing, mineral ore grinding, carbon in pulp gold recovery, minerals industry and extractive metallurgical industry (Kingman and Rowson 1998), processing of waste (Appleton et al 2005) and food industry (Zhang $\mathrm{M}$ et al 2006; Biswas et al 2007). However, difficulties associated with the scaling up of the laboratory units to industrial capacities and lack of fundamental data on material dielectric properties are the obstacles for the widespread use of microwave processing (Jones et al 2002).

\section{Role of electric and magnetic field components}

Current research on the effects of $\mathrm{E}$ and $\mathrm{H}$ field components of the microwave field in the heating behaviour of

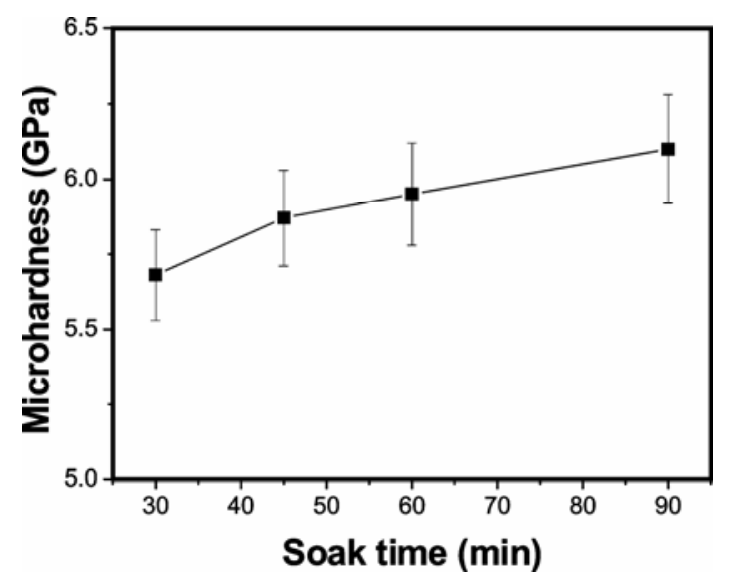

Figure 12. Typical hardness of the microwave processed glass-ceramic coatings.

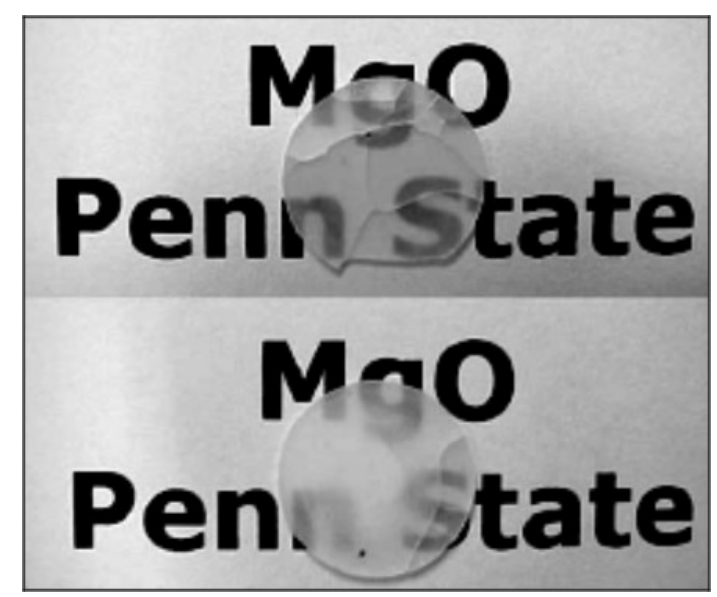

Figure 13. As-annealed translucent $\mathrm{MgO}$ pellet (Fang et al 2004a). metal, ceramic and metal-ceramic composite samples showed that powdered metal compacts were effectively heated in the $\mathrm{H}$ field, but not in the $\mathrm{E}$ field while solid metallic rod could not be heated either in the E field or in the $\mathrm{H}$ field at all. In contrast, ceramics and insulators could be rapidly heated in the E field but not in the $\mathrm{H}$ field. Furthermore, metal-ceramic composites could be heated up in both $\mathrm{E}$ and $\mathrm{H}$ microwave fields (Cheng et al $2001 b, 2002 a)$. Therefore, it is no longer possible to ignore the effect of the magnetic component for the general theory of energy loss in various materials when placed in a microwave field, especially for conductor and semiconductor materials. The contributions to the magnetic loss mechanism can be hysteresis, eddy currents, magnetic resonance and domain wall oscillations. Hence, it is necessary to incorporate the effects of the magnetic field in the microwave-material interaction (Cheng et al 2002b).

\section{Modeling of microwave heating}

New and unexpected physical behaviours such as the hot spot often occur during microwave processing. Therefore, it is necessary to develop the simplified mathematical models from which the occurrence of such phenomena can be predicted. Some of the recent developments in the mathematical modelling of microwave heating are: (a) models that consider isolation of the heat equation with a nonlinear source term assuming the electric-field amplitude as constant, (b) models that involve the coupling between the electric-field amplitude and temperature including both steady-state solutions and the initial heating, (c) models that control thermal runaway and (d) numerical models that elaborate on the microwave heating process (Jolly and Turner 1990; Hill and Pincombe 1991; Kriegsmann 1992; Hill and Jennings 1993; Hill and Marchant 1996; Mercado et al 2002; Moitsheki and Makinde 2007).

\section{Future research}

There is a huge scope to extend the microwave technology in broad zones including the following specific areas:

- Processing of specialty ceramics, bio-ceramics, bioceramic coatings;

- Synthesis of new, novel ceramic powders;

- Synthesis of whiskers, microtubes and nanotubes;

- Joining of ceramics;

- Fabrication of glass-ceramic coatings;

- Development of core-shell type composites;

- Sintering of powdered metal and understanding of the sintering mechanism;

- Analysis of the role of the $\mathrm{H}$ field in microwavematerial interaction;

- Modelling of microwave heating. 

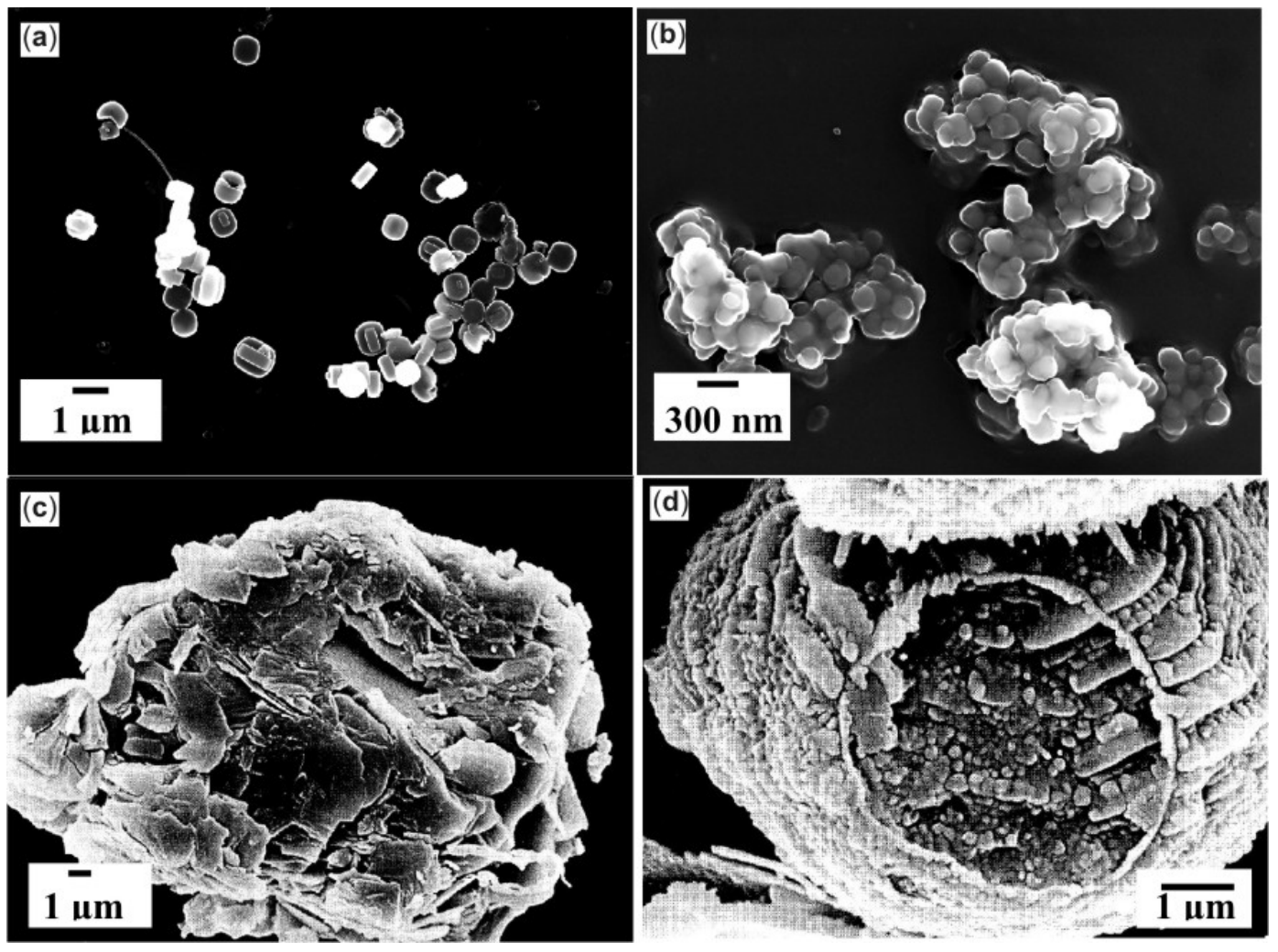

Figure 14. SEM micrographs of (a) as-received $\mathrm{Al}$ powder particles, (b) microwave-oxidized $\mathrm{Al}$ powder particles, (c) as-received $\mathrm{Al}$ powder agglomerate and (d) microwave-oxidized $\mathrm{Al}$ powder agglomerate.

Our laboratory based microwave technology should be successfully exploited for commercial applications overcoming the limitations and difficulties faced in scaling up the operations.

\section{Conclusions}

In the past decades significant developments have taken place in the field of microwave processing of materials. However, more research must be conducted to obtain a detailed understanding about the nature and distribution of the electromagnetic field inside the microwave cavity, microwave-material interaction, material transformations and heat transfer mechanisms for optimizing the process. Since microwave processing is a relatively new technology, considerable time may be required to implement this technology for the ceramic industry. It is hoped that significant advancements will take place in the science and technology of microwave processing so that one can envisage the introduction of batch type microwave sintering furnaces in the production units of ceramic industries.

\section{Acknowledgements}

The authors are thankful to Mr A K Mandal, Mrs S Roy, Dr A K Chakraborty, Mr S K Dalui, Mr A Karmakar and Mr B Chakraborty for their experimental assistance.

\section{References}

Agrawal D 2005a High Tech Ceram. News 169 Agrawal D 2005b Ind. Heat. 7237

Agrawal D 2006 Trans. Ind. Ceram. Soc. 65129

Agrawal D, Raghavendra R and Vaidhyanathan B 2002 US patent No. 6,399,012

Agrawal D, Cheng J, Peelamedu R and Roy R 2004 Curr. Adv. Mater. and Process. 17670

Agrawal D K 1998 Curr. Opin. Solid State \& Mater. Sci. 3480

Al-Assafi S, Ahmad I, Fathi Z and Clark D E 1991 Ceramic transactions (eds) D E Clark et al (Westerville, Ohio: The Am. Ceram. Soc., Inc.) 21 p. 515

Ananthakumar S et al 1998 Br. Ceram. Trans. 97236

Anon 2001 Am. Ceram. Soc. Bull. 8038

Appleton T J, Colder R I, Kingman S W, Lowndes I S and Read A G 2005 Appl. Ener. 8185

Apte S K, Naik S D, Sonawane R S, Kale B B, Pavaskar N, Mandale A B and Das B K 2006 Mater. Res. Bull. 41647

Aravindan S and Krishnamurthy R 1999 Mater. Lett. 38245

Barmatz M, Jackson H and Radtke R 2000 US patent No. 6, 054,693

Berteaud A J and Badot J C 1976 J. Microwave Power 11315

Binner J G P, Hassine N A and Cross T E 1995 Ceram. trans. (eds) D E Clark et al (Westerville, Ohio: The Am. Ceram. Soc., Inc.) 59 p. 565

Biswas A, Adhvaryu A, Stevenson D G, Sharma B K, Willet J L and Erhan S Z 2007 Ind. Crops \& Prod. 251

Boccaccini A R, Veronesi P and Leonelli C 2001 J. Euro. Ceram. Soc. 211073 
Breval E, Cheng J P, Agrawal D K, Gigl P, Dennis M, Roy R and Papworth A J 2005 Mater. Sci. \& Eng. A391 285

Cawley J D 1998 Am. Ceram. Soc. Bull. 681619

Chen M, Siochi E J, Ward T C and McGrath J E 1993 Polym. Eng. \& Sci. 331092

Cheng J, Agrawal D and Roy R 1999 J. Mater. Sci. Lett. 18 1989

Cheng J, Agrawal D, Zhang Y and Roy R 2001a J. Mater. Sci. Lett. 2077

Cheng J, Roy R and Agrawal D 2001b J. Mater. Sci. Lett. 20 1561

Cheng J, Agrawal D, Zhang Y and Roy R 2002a J. Electroceram. 967

Cheng J, Roy R and Agrawal D 2002b Mater. Res. Innovat. 5 170

Cheng J, Guo R and Wang Q M 2004 Appl. Phys. Lett. 855140

Cirakoglu M, Bhaduri S and Bhaduri S B 2002 J. Mater. Res. 172823

Clark D and Sutton W H 1996 Annu. Rev. Mater. Sci. 26299

Cozzi A D, Fathi Z and Clark D E 1993 Ceram. trans. (eds) D E Clark et al (Westerville, Ohio: The Am. Ceram. Soc., Inc.) 36 p. 317

Dai C, Zhang X, Zhang J, Yang Y, Cao L and Xia F $1997 \mathrm{~J}$. Am. Ceram. Soc. 801274

Das S, Mukhopadhyay A K, Datta S and Basu D 2003a J. Mater. Sci. Lett. 221635

Das S, Basu D, Datta S and Mukhopadhyay A K 2003b Indian Patent application No. 57/DEL/03

Das S, Mukhopadhyay A K, Datta S and Basu D 2005 Trans. Ind. Ceram. Soc. 64143

Das S, Mukhopadhyay A K, Datta S and Basu D 2006 Trans. Ind. Ceram. Soc. 65105

Das S, Mukhopadhyay A K, Datta S, Das G C and Basu D 2008a J. Euro. Ceram. Soc. 28729

Das S, Mukhopadhyay A K, Datta S and Basu D 2008b (communicated)

Duval D J, Phillips B L, Terjak M J E and Risbud S H 1997 J. Solid State Chem. 131173

Fang Y, Agrawal D K, Roy D M and Roy R 1992 J. Mater. Res. 7490

Fang Y, Roy D M, Cheng J, Roy R and Agrawal D K 1993 Ceramic transactions (eds) D E Clark et al (Westerville, Ohio: The Am. Ceram. Soc., Inc.) 36 p. 397

Fang Y, Agrawal D K, Roy D M and Roy R 1994 J. Mater. Res. 9180

Fang Y, Agrawal D K, Roy D M and Roy R 1995 Mater. Lett. 23147

Fang Y, Chen Y, Silsbee M R and Roy D M 1996a Mater. Lett. 27155

Fang Y, Roy D M and Roy R 1996b Cem. \& Concr. Res. 2641

Fang Y, Agrawal D, Skandan G and Jain M 2004a Mater. Lett. 58551

Fang Y, Agrawal D, Lanagan M, Shrout T, Randall C, Randall M and Henderson A 2004b Ceram. trans. (ed.) K M Nair (Westerville, Ohio, USA: The American Ceramic Society) 150 p. 359

Fathi Z, Tucker D A, Lewis W A and Wei J B 1996 Microwave processing of materials V, Mater. Res. Soc. Symp. Proc. (eds) M F Iskander et al (Pittsburgh, Pennsylvania: Materials Research Society) 430 p. 21

Fu Y -P 2006 Mater. Res. Bull. 41809
Fukushima H, Yamanaka T and Matsui M 1990 J. Mater. Res. 5 397

Gedevanishvili S, Agrawal D and Roy R 1999 J. Mater. Sci. Lett. 18665

Gerdes T et al 1996 Microwave processing of materials $V$, in Materials research society symposium proceedings (eds) M F Iskander et al (Pittsburgh, Pennsylvania: Materials Research Society) 430 p. 45

Goldstein A, Giefman L and Bar Ziv S 1998 J. Mater. Sci. Lett. 17977

Goldstein A, Travitzky N, Singurindy A and Kravchik M 1999 J. Euro. Ceram. Soc. 192067

Gómez I, Hernández M, Aguilar J and Hinojosa M 2004 Ceram. Int. 30893

Groza J R, Risbud S H and Yamazaki K 1992 J. Mater. Res. 7 2643

Guerga M H and Hailler B L D 1973 U.S. Pat. No. 3,732,048

Haran E N, Gringas H and Katz D 1965 J. Appl. Polym. Sci. 9 3505

Hart J N, Cheng Y -B, Simon G P and Spiccia L 2005 Surf. \& Coat. Technol. 19820

Hassler Y and Johansen L 1988 Microwave processing of materials (eds) W H Suttan et al (Pittsburgh, PA: Materials Research Society) 124 p. 273

Hill J M and Pincombe A H 1991 J. Aust. Math. Soc. Ser. B33 290

Hill J M and Jennings M J 1993 Appl. Math. Model. 17369

Hill J M and Marchant T R 1996 Appl. Math. Model. 203

Hsu C S and Huang C L 2001 Mater. Res. Bull. 361939

Huang C L et al 2001 Mater. Res. Bull. 36683

Huang S G, Li L, Van der Biest O and Vleugels J 2007 J. Eur. Ceram. Soc. 27689

Jena H and Rambabu B 2007 Mater. Chem. \& Phys. 10120

Jolly P G and Turner I W 1990 J. Microwave Power Electromag. Energy 253

Jones D A, Lelyveld T P, Mavrofidis S D, Kingman S W and Miles N J 2002 Resources, Conservation and Recycling 34 75

Kamo M, Sato Y, Matsumoto S and Setaka N 1983 J. Cryst. Growth 62642

Katakam S, Siva Rama Krishna D, Murugan R and Sampath Kumar T S 2003 Trends Biomater. Artif. Organ. 1724

Kemer E L and Johnson D L 1985 Am. Ceram. Soc. Bull. 64 1132

Khollam Y B, Deshpande S B, Khanna P K, Joy P A and Potdar H S 2004 Mater. Lett. 582521

Kingman S W and Rowson N A 1998 Miner. Eng. 111081

Komarneni S and Roy R 1986 Mater. Letts 4107

Kriegsmann G A 1992 Mater. Res. Soc. Symp. Proc. 269257

Krupa A A et al 1993 Glass Ceram. 5034

Kutty M G et al 2001 Ceram. Engg. Sci. Proc. 223

Lee D W and Kim B K 2004 Mater. Lett. 58378

Lee K Y and Case E D 1999 J. Mater. Sci. Lett. 18201

Lee W I and Springer G S 1984 J. Comp. Mater. 18387

Leonelli C, Pellacani G C, Siligardi C and Veronesi P 2004 Key Eng. Mater. 264-268 739

Lo C L et al 2002 J. Am. Ceram. Soc. 852230

Long S, Dong J and Yan C 2002 Cem. \& Concr. Res. 32 1653

Mandal S, Seal A, Dalui S K, Dey A K, Ghatak S and Mukhopadhyay A K 2001 Bull. Mater. Sci. 24121 
Mathis M D, Agrawal D K, Roy R, Plovnick R H and Hutcheon R M 1995a Ceramic transactions (eds) D E Clark et al (Westerville, Ohio: The Am. Ceram. Soc., Inc.) 59 p. 557

Mathis M D, Agrawal D K, Roy R and Plovnick R H 1995b Ceram. Trans. (eds) D E Clark et al (Westerville, Ohio: The Am. Ceram. Soc., Inc.) 59 p. 533

Meek T T and Blake R D 1986 J. Mater. Sci. Lett. 5270

Mercado G A, Luce B P and Xin J 2002 IMA J. Appl. Math. 67 419

Metaxas A C 1993 Ceramic transactions (eds) D E Clark et al (Westerville, Ohio: The Am. Ceram. Soc., Inc.) 36 p. 549

Moitsheki R J and Makinde O D 2007 Appl. Math. \& Comput. 191308

Mukhopadhyay A K, Roy Chaudhury M, Seal A, Dalui S K, Banerjee M and Phani K K 2001 Bull. Mater. Sci. 24125

Nan Lin I, Lee W -C, Liu K -S, Cheng H -F and Wu M -W 2001 J. Eur. Ceram. Soc. 212085

Ni Y, Ma X, Hong J and Xu Z 2004 Mater. Letts 582754

Oh S T et al 2001 Mater. Lett. 48215

Palaith D and Silberglitt R 1989 Ceram. Bull. 681601

Pitisescu R R, Barbara M, Marija K, Motoc A, Monty C, Iulia S, Kosmac T and Daskobler A 2004 J. Euro. Ceram. Soc. 24 1941

Quemeneur L, Choisnet J, Raveau B, Thiebaut J M and Roussy G 1983a J. Am. Ceram. Soc. 66855

Quemeneur L, Choisnet J and Raveau B 1983b Mater. Chem. Phys. 8293

Ramesh P D, Vaidhyanathan B, Ganguli M and Rao K J 1994 J. Mater. Res. 91

Ramesh S, Tan C Y, Bhaduri S B and Teng W D 2007 Ceram. Int. 331363

Rao K J, Vaidhyanathan B, Ganguli M and Ramakrishnan P A 1999 Chem. Mater. 88211

Rao K J, Mahesh K and Kumar S 2005 Bull. Mater. Sci. 28 19

Rhee S, Agrawal D, Shrout T and Thumm M 2001 Ferroelectrics 26115

Rodríguez-Lorenzo L M, Vallet-Regí M, Ferreira J M F, Ginebra M P, Aparicio C and Planell J A 2003 J. Biomed. Mater. Res. 60159

Roy R, Komarneni S and Yang L J 1985 J. Am. Ceram. Soc. 68 392

Roy R, Agrawal D, Cheng J and Gedevanishvili S 1999 Nature 399668

Roy R, Fang Y, Cheng J and Agrawal D K 2005 J. Am. Ceram. Soc. 881640

Ryu J H, Koo S -M, Yoon J -W, Lim C S and Shim K B 2006 Mater. Letts 601702

Saitou K 2006 Scr. Mater. 54875

Segerer H 1998 Am. Ceram. Soc. Bull. 7764

Seyrankaya A and Ozalp B 2006 Thermochim. Acta 44831
Sharma A K, Aravindhan S and Krisnamurthy R 2001 Mater. Letts $\mathbf{5 0} 295$

Sieke C 1993 Cfi/Ber DKG 70534

Siligardi C, Leonelli C, Bondioli F, Corradi A and Pellacani G C 2000 J. Euro. Ceram. Soc. 20177

Siligardi C, Leonelli C, Fang Y and Agrawal D 1996 Microwave processing of materials $V$ in Mater. Res. Soc. Symp. Proc. (eds) M F Iskander et al (Pennsylvania, Pittsburgh: Materials Research Society) Vol. 430

Sundar Manoharan S, Goyal S, Rao M L, Nair M S and Pradhan A 2001 Mater. Res. Bull. 361039

Sutton W H 1989 Ceram. Bull. 68376

Thostenson E T and Chou T -W 1999 Composites: Part A 30 1055

Travitzky N A, Goldstein A, Avsian O and Singurindi A 2000 Mater. Sci. \& Eng. A286 225

Tun K S and Gupta M 2007 Comp. Sci. \& Technol. 672657

U.S. Bureau of Mines 1983 Technol. News No. 185

Upadhyaya D D, Ghosh A, Gurumurthy K R and Prasad R 2001 Ceram. Int. 27415

Vadivel Murugan A, Samuel V and Ravi V 2006 Mater. Letts 60479

Vaidhyanathan B, Agrawal D K, Shrout T R and Fang Y 2000 Mater. Lett. 42207

Vaidhyanathan B, Agrawal D and Roy R 2004 J. Am. Ceram. Soc. 87834

Varma H K, Ananthakumar S, Warrier K G K and Damodaran A D 1996 Ceram. Int. 2253

Watawe S C, Keluskar S, Gonbare and Tangsali R 2006 Thin Solid Films $\mathbf{5 0 5} 168$

Wong W L E and Gupta M 2007 Compos. Sci. \& Technol. 67 1541

Wu X, Jiang Q -Z, Ma Z -F, Fu M and Shangguan W-F 2005 Solid State Commun. 136513

Xie Z, Gui Z, Li L, Su T and Huang Y 1998 Mater. Lett. 36191

Xie Z, Yang J and Huang Y 1999 J. Euro. Ceram. Soc. 19381

Yadoji P, Peelamedu R, Agrawal D and Roy R 2003 Mater. Sci. \& Eng. B98 269

Yoon S Y, Park Y M, Park S S, Stevens R and Park H C 2005 Mater. Chem. \& Phys. 9148

Yoon D -M, Yoon B -J, Lee K -H, Kim H S and Park C G 2006 Carbon 441298

Zeng L, Case E D and Crimp M A 2003 Mater. Sci. \& Eng. A357 67

Zhang G, Leparoux S, Liao H and Coddet C 2006 Scr. Mater. 55621

Zhang L -X, Liu P and Su Z-X 2006 Mater. Res. Bull. 411631

Zhang M, Tang J, Mujumdar A S and Wang S 2006 Trends Food Sci. \& Technol. 17524

Zhou B, Zhao Y, Pu L and Zhu J -J 2006 J. Power Sources 154 239 